\title{
Cytotoxicity of Southeast Asian snake venoms
}

Jamunaa A (1), Vejayan J (2), Halijah I (1), Sharifah SH (2), Ambu S (3)

(1) Institute of Biological Sciences, University of Malaya, Kuala Lumpur, Malaysia; (2) School of Medicine and Health Sciences, Monash University, Bandar Sunway, Selangor Darul Ehsan, Malaysia; (3) International Medical University, Kuala Lumpur, Malaysia.

\begin{abstract}
Cytotoxicity of venoms from eleven medically important snakes found in Southeast Asia (Naja kaouthia, Naja siamensis, Naja sumatrana, Ophiophagus hannah, Bungarus candidus, Bungarus fasciatus, Enhydrina schistosa, Calloselasma rhodostoma, Trimeresurus purpureomaculatus and Tropidolaemus sumatranus) was determined, based on the MTS cytotoxicity assay, which determines the survival of viable cells in monolayer MDCK and Vero cell cultures upon exposure to the snake venoms. Snake venom toxicity was expressed as the venom dose that killed $50 \%$ of the cells $\left(\mathrm{CTC}_{50}\right)$ under the assay conditions. Venoms of C. rhodostoma $(2.6 \mu \mathrm{g} / \mathrm{mL}, 1.4 \mu \mathrm{g} / \mathrm{mL})$ and $O$. hannah were the most cytotoxic $(3.8 \mu \mathrm{g} / \mathrm{mL}, 1.7$ $\mu \mathrm{g} / \mathrm{mL})$ whereas $N$. siamensis venom showed the least cytotoxicity $(51.9 \mu \mathrm{g} / \mathrm{mL}, 45.7 \mu \mathrm{g} / \mathrm{mL})$ against Vero and MDCK cells, respectively. All the viper venoms showed higher cytotoxic potency towards both Vero and MDCK cell lines, in comparison to krait and cobra venoms. E. schistosa did not cause cytotoxicity towards MDCK or Vero cells at the tested concentrations. The cytotoxicity correlates well with the known differences in the composition of venoms from cobras, kraits, vipers and sea snakes.
\end{abstract}

Key words: cytotoxicity, snake venom, vipers, elapids, kraits.

\section{INTRODUCTION}

Venomous snakebites are a significant yet neglected medical problem worldwide, especially in developing countries (1). In Malaysia, as many as 55,000 snakebite cases were admitted to hospitals during the period from 1958 to 1980 (2). The statistics and data for snakebite epidemiology in Malaysia are normally inadequate and inaccurate because countless ophidian accident victims choose to be treated by traditional healers and thus do not seek proper treatment in hospitals.

The venomous snakes of Southeast Asia can be generally divided into two important families, Elapidae and Viperidae. Elapidae includes cobras, king cobras, kraits, coral snakes and sea snakes. Viperidae can be divided into two subgroups, the typical vipers (Viperinae) and pit vipers (Crotalinae) (3). The medically important species in Southeast Asia include Naja kaouthia (Elapidae), Naja siamensis (Elapidae), Naja sumatrana (Elapidae), Ophiophagus hannah (Elapidae), Bungarus candidus (Elapidae), Bungarus fasciatus (Elapidae), Enhydrina schistosa (Elapidae), Calloselasma rhodostoma (Viperidae), Trimerusurus wagleri (Viperidae), Trimerusurus purpureomaculatus (Viperidae) and Trimerusurus sumatranus (Viperidae).

Snakevenoms are known to be the most complex of all natural venoms. They contain more than one hundred toxic and non-toxic proteins and peptides as well as non-protein toxins, carbohydrates, lipids, amines, and other small molecules (4). Snake venom composition varies within species, 
subspecies or even in a single specimen; depending on the geography, age, season and diet of the snake. Snake venom is an amazing natural toxin source which has undergone unique adaptations to animal evolution. Usually, snake venoms are classified according to an entire snake family; as such, viper venoms are often characterized as hemorrhagic, whereas elapid venoms are denominated paralytic. But, this method is often misleading because each species presents a unique cocktail of many venom components including cytotoxins, neurotoxins, cardiotoxins, myotoxins, hemorrhagins, coagulants/anticoagulants, nephrotoxins and others (5). Thus, each venom differs as to component content and quantity, which in turn reflects the variation in the clinical manifestation of the snakebite.

The cell toxicity assay has been adapted as an alternative to assess toxicity in animals. It is a simple, economical, time-saving yet sensitive method which produces results that are highly comparable among different types of venoms in the laboratory (6). In the present study, our aim was to determine the cytotoxic value of medically important snake venoms indigenous to Southeast Asia through an in vitro system of green monkey kidney cells (Vero) and Madine-Darby canine kidney cells (MDCK) using the Promega CellTiter 96 Aqueous One-Solution Cell Proliferation (USA) assay which contains a tetrazolium compound [3-(4,5-dimethylthiazol-2-yl)-5-(3carboxymethoxyphenyl)-2-(4-sulfophenyl)-2Htetrazolium, inner salt; MTS] and an electron coupling reagent (phenazine ethosulfate - PES). Protein contents of the venoms produced by cobras, king cobras, kraits, sea snakes, vipers and pit-vipers will be compared with their cytotoxic potency to evaluate the different types of venoms.

\section{MATERIALS AND METHODS}

\section{Venom and Reagents}

Sterile plastic materials for cell culture were supplied by Corning (USA). Cell culture media and supplements were purchased from Invitrogen (USA). Venoms were purchased from Bukit Bintang Enterprise Sdn Bhd, Perlis, Malaysia, lyophilized and stored at $-20^{\circ} \mathrm{C}$.

\section{Bradford Protein Determination}

One hundred microliters of bovine serum albumin (BSA) standard consisting of $0,2,4,6$,
8 and $10 \mu \mathrm{g}$ of protein content and 11 diluted venom samples were mixed with $1 \mathrm{~mL}$ Bradford reagent in microcentrifuge tubes. Absorbance of Bradford-protein complexes was measured after 20 minutes at $595 \mathrm{~nm}$ in microcuvettes using a Shimadzu UV-1800 spectrophotometer (Japan). A standard curve of BSA protein at different concentrations was plotted to enable the determination of the protein concentrations in the 11 venom samples.

\section{Venom Preparation}

A total of 11 venom samples, stored as dry powders at $-20^{\circ} \mathrm{C}$, were analyzed: Naja kaouthia, Naja siamensis, Naja sumatrana, Ophiophagus hannah, Bungarus candidus, Bungarus fasciatus, Enhydrina schistosa, Calloselasma rhodostoma, Trimerusurus wagleri, Trimerusurus purpureomaculatus and Trimerusurussumatranus. A venom solution with $5 \mathrm{CTC}_{50}$ strength was prepared from each of the venom's $50 \%$ cytotoxic concentration by dissolving varying amount of venom powders in ice-cold minimum essential media (MEM) without fetal bovine serum.

\section{Cell Culture}

MDCK (ATCC n. CRL-2936) and Vero (ATCC n. CCL-81) cells were obtained from American Type Culture Collection (ATCC). The cells were grown in plastic flasks at $37^{\circ} \mathrm{C}$, in a mixture of $5 \%$ $\mathrm{CO}_{2}$ and $95 \%$ air, with minimal essential medium (MEM) supplemented with $10 \%$ fetal calf serum (FCS) and 1\% HEPES. The medium was changed and cells were subcultured every three days.

\section{Cytotoxicity Assay}

The adherent cell lines were detached from the culture flasks by adding $1 \mathrm{~mL}$ of $0.025 \%$ trypsin solution for ten minutes at $37^{\circ} \mathrm{C}$. The trypsin was inactivated by adding $5 \mathrm{~mL}$ of $10 \%$ FBS in MEM medium. Cells were then centrifuged at 2000 $\mathrm{rpm}$, for ten minutes at $4^{\circ} \mathrm{C}$, and then counted using $0.4 \%$ Trypan Blue dye exclusion method. Five thousand cells per $50 \mu \mathrm{L}$ of medium were seeded into each well of a 96-well microtiter plate prior to the MTS cytotoxicity assay.

Cytotoxicity testing was performed using the Promega Cell Titer $96^{\circ}$ Aqueous One Solution Cell Proliferation Assay (USA) to determine the number of viable cells in the culture. The test protocol was modified from Oliveira et al. (6). Venoms were suspended in culture media and 
diluted across the 96-well microtiter plates (50 $\mu \mathrm{L})$ containing Vero/ MDCK cells $(5,000$ cells/50 $\mu \mathrm{L} /$ well). The plates were incubated for 30 minutes at $37^{\circ} \mathrm{C}$ with $5 \% \mathrm{CO}_{2}$. MTS reagent (20 $\mu \mathrm{L} /$ well) was added at the end of 30 minutes and further incubated for three hours. Absorbance readings were taken at $492 \mathrm{~nm}$ after the threehour incubation period.

\section{Statistical Analysis}

All results were expressed as the mean \pm SD. GraphPad Prism 5 software (USA) was used for variance analysis (standard deviation calculation) and determination of the $50 \%$ cytotoxic concentration $\left(\mathrm{CTC}_{50}\right)$ of the snake venoms.

\section{RESULTS}

\section{Comparison of the Cytotoxic Activity of} Vipers, Cobras and Sea Snakes

Cytotoxicity $\left(\mathrm{CTC}_{50}\right)$ was estimated by curve interpolation, as the venom dose resulting in $50 \%$ death of MDCK and Vero cell populations, after plotting the mean percentage of surviving cells against the concentration of venom solution (milligram of dry weight per milliliter). Negative control was taken as $100 \%$ survival. Apamin, a-bungarotoxin and tamoxifen were used as standards in this study.

The cytotoxicity curves obtained for snake venoms in Vero and MDCK are shown in Figure 1 and Figure 2 respectively. Figure $1-\mathrm{D}$ and Figure $2-\mathrm{D}$ display the cytotoxicity curves obtained for the standards tamoxifen, a-bungarotoxin and apamin in Vero and MDCK cells respectively, whereas Figure 3 shows the 50\% cytotoxic concentration $\left(\mathrm{CTC}_{50}\right)$ of the following 11 snake venoms: Naja kaouthia (NK), Calloselasma rhodosthoma (CR), Ophiophagus hannah $(\mathrm{OH})$, Bungarus candidus (BC), Bungarus fasciatus (BF), Trimeresurus purpureomaculatus (TP), Trimeresurus sumatranus (TS), Trimeresurus wagleri (TW), Naja Siamensis (NS), Naja sumatrana (NSU) and Enhydrina schistosa (ES).

Of the ten snake venoms $\mathrm{CR}$ showed the lowest $\mathrm{CTC}_{50}$ concentration against MDCK cells $(1.4 \mu \mathrm{g} /$ $\mathrm{mL})$, followed by KC $(1.7 \mu \mathrm{g} / \mathrm{mL})$; NS $(45.7 \mu \mathrm{g} /$
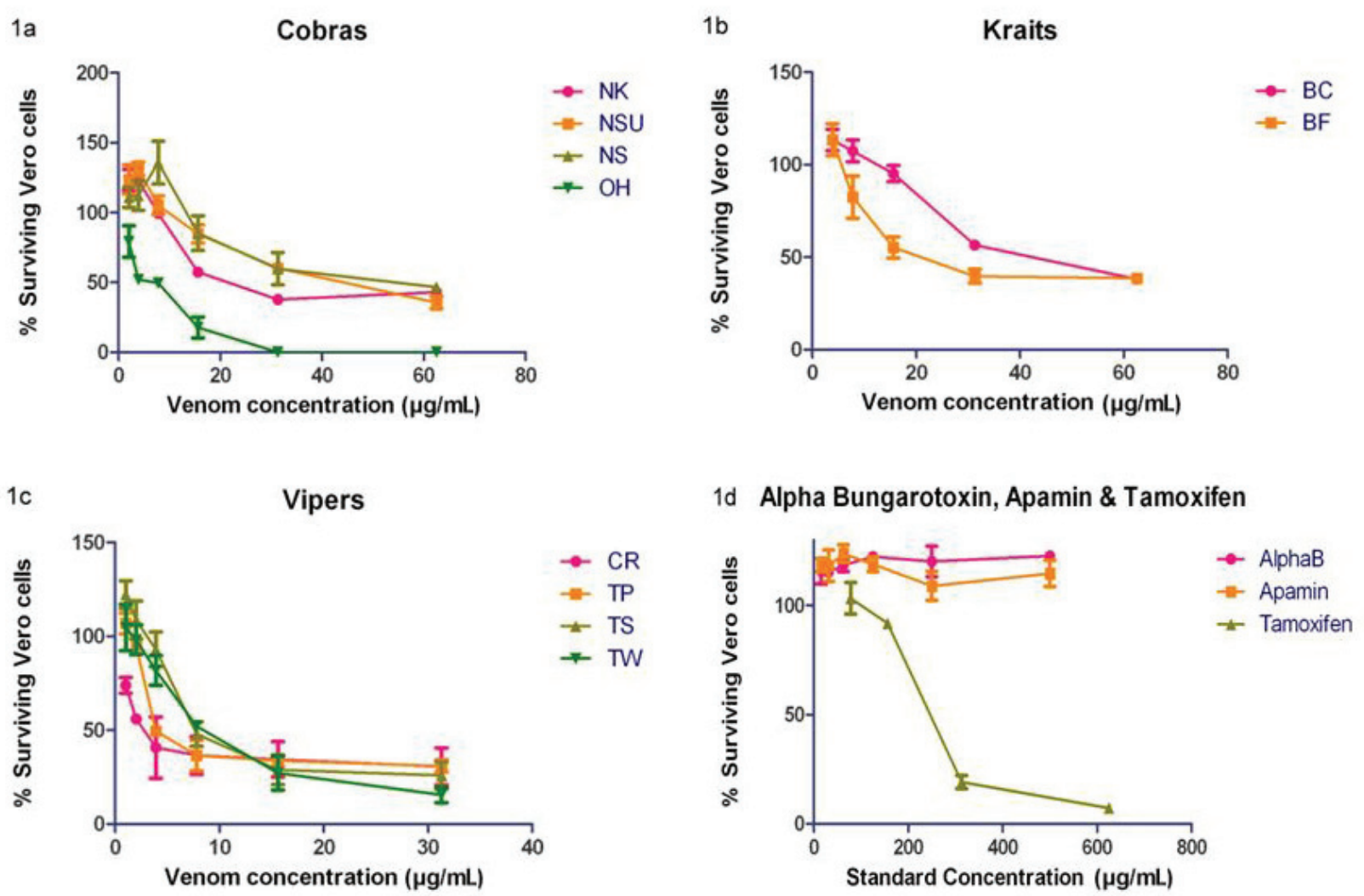

Figure 1. Cytotoxicity curves of snake venoms and standards in Vero cells. For each venom sample $(n=3)$; experiments were repeated three times and the results are displayed as mean values. Points are the means and bars are the SD values. 


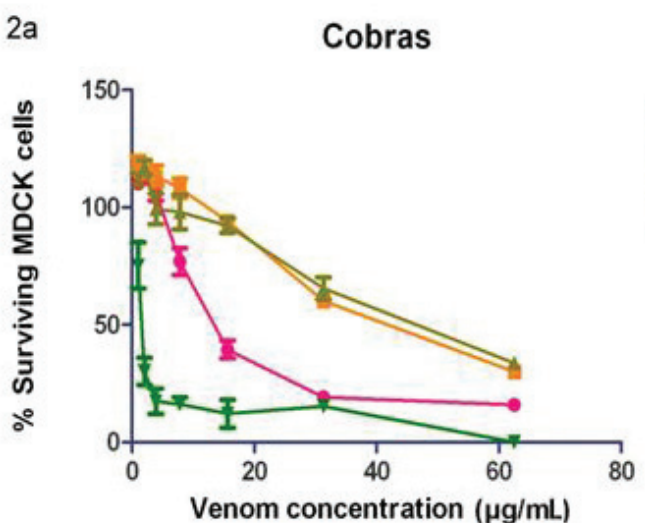

2c

Vipers

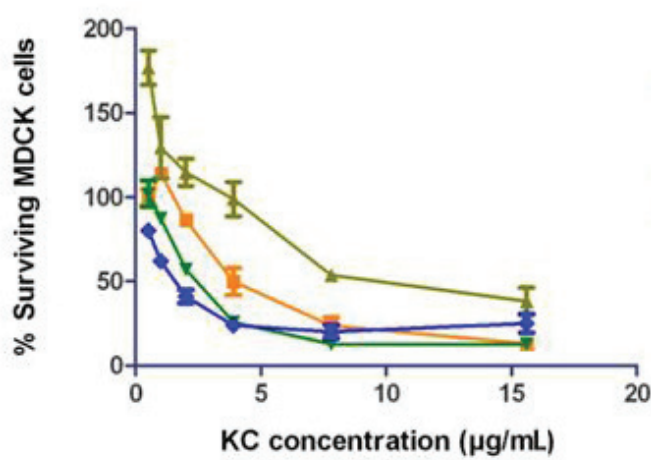

$2 \mathrm{~b}$

Kraits

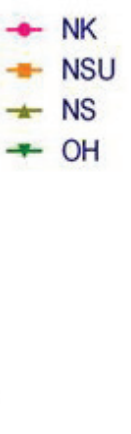

2d Alpha Bungarotoxin, Apamin \& Tamoxifen
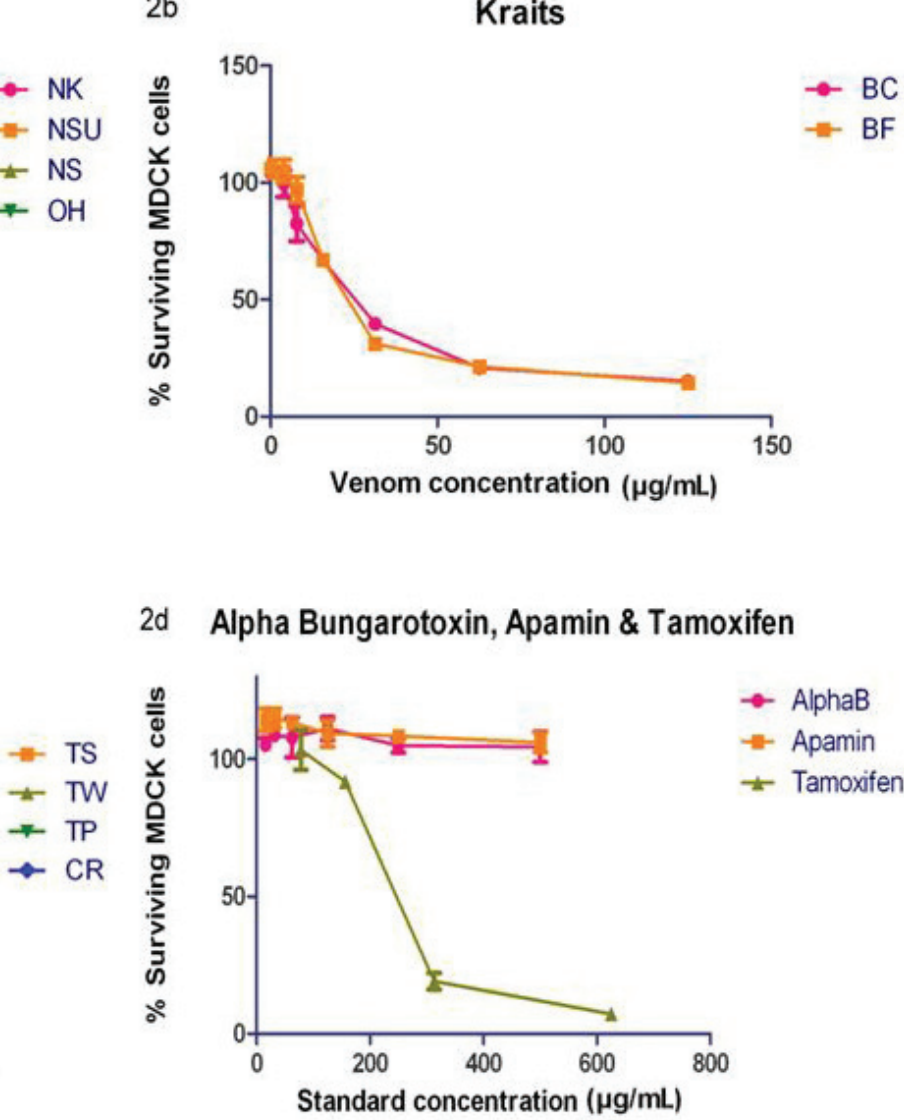

Figure 2. Cytotoxicity curves of snake venoms and standards in MDCK cells. For each venom sample $(n=3)$; experiments were repeated three times and the results are displayed as mean values. Points are the means and bars are the SD values.

\section{$\mathrm{CTC}_{50}(\mu \mathrm{g} / \mathrm{mL})$ of Malaysian snake venoms}

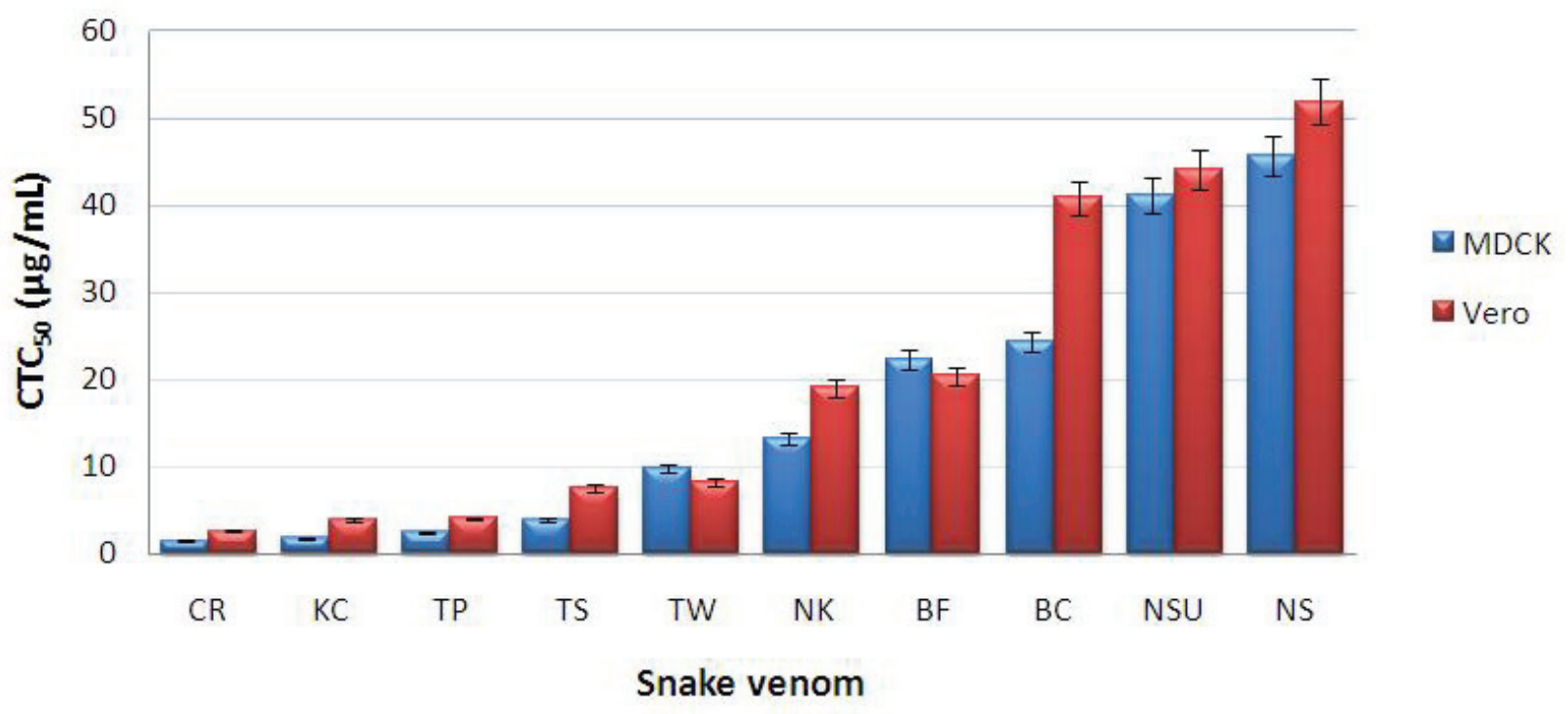

*ES venom's $\mathrm{CTC}_{50}$ value was not detectable in both cells

Figure 3. Cytotoxicity of Malaysian snake venoms against MDCK and Vero cells obtained by the MTS cell culture assay. 
Table 1. $\mathrm{CTC}_{50}$ concentration $(\mu \mathrm{g} / \mathrm{mL})$ of snake venoms in MDCK and Vero cell lines

\begin{tabular}{c|c|c}
\hline Snake venom & $(\mu \mathrm{g} / \mathrm{mL})$ in MDCK cells & $(\mu \mathrm{g} / \mathrm{mL})$ in Vero cells \\
\hline Calloselasma rhodostoma (CR) & 1.4 & 2.6 \\
\hline Ophiophagus hannah (KC) & 1.7 & 3.8 \\
\hline Trimerusurus purpureomaculatus (TP) & 2.4 & 4.0 \\
\hline Trimerusurus sumatranus (TS) & 3.9 & 7.5 \\
\hline Trimerusurus wagleri (TW) & 9.7 & 8.2 \\
\hline Naja kaouthia (NK) & 13.2 & 19.0 \\
\hline Bungarus fasciatus (BF) & 22.3 & 20.4 \\
\hline Bungarus candidus (BC) & 24.3 & 40.8 \\
\hline Naja sumatrana (NSU) & 41.2 & 44.1 \\
\hline Naja siamensis (NS) & 45.7 & 51.9 \\
\hline
\end{tabular}

${ }^{*} \mathrm{CTC}_{50}$ of Enhydrina schistosa (ES) was not detectable in either MDCK or Vero cell line.

$\mathrm{mL}$ ) was the least cytotoxic. The same pattern was observed in Vero cells with CR presenting the lowest $\mathrm{CTC}_{50}$ concentration $(2.6 \mu \mathrm{g} / \mathrm{mL})$, followed by KC $(3.8 \mu \mathrm{g} / \mathrm{mL})$; NS $(51.9 \mu \mathrm{g} / \mathrm{mL})$ was the least cytotoxic of the ten venoms. The $\mathrm{CTC}_{50}$ venom concentrations are given in Table 1.

All venoms except ES expressed a dosedependent cytotoxicity against the two cell lines tested, namely Vero and MDCK cells. The highest and lowest cytoxicities were displayed by CR and NSU venoms, respectively, against both the MDCK and Vero cell lines. Apamin and a-bungarotoxin were used as standards along with tamoxifen. Apamin and $\alpha$-bungarotoxins showed no cytotoxicity towards either MDCK or Vero cells, whereas tamoxifen standard presented a $\mathrm{CTC}_{50}$ concentration of $247.0 \mu \mathrm{g} / \mathrm{mL}$ against both MDCK and Vero cells.

\section{DISCUSSION AND CONCLUSION}

The purpose of this investigation is to evaluate and compare the cytotoxicity of snake venoms commonly found in the tropical region of Malaysia by the MTS cytotoxicity assay. To date, there are very few published works that have studied and compared the cytotoxicity of venoms from different snake species in one study and none assessing snakes found in Malaysia $(6,7)$. The most useful information found by this assay is the number of viable cells at the end of the snake venom treatment. This parameter is highly convenient given that the number of viable cells in culture is an indicator of active metabolism.

The results of $\mathrm{CTC}_{50}$ concentration of the venoms from 11 snake species commonly found in Malaysia reveal a clear pattern of their activity towards the cells. CR has the highest cytotoxicity value against MDCK cells, followed by $\mathrm{OH}, \mathrm{TP}, \mathrm{TS}, \mathrm{TW}, \mathrm{NK}, \mathrm{BF}, \mathrm{BC}$, NSU and lastly NS. Investigation of venoms reveals similar cytotoxicity to Vero and MDCK cells. The results on both cells clearly show that pit vipers exert very high cytotoxicity, followed by kraits and cobras. Though each viper's venom is different, they are mainly hemotoxic, thus affecting the circulatory system by destroying blood cells, blood vessels and eventually the heart, causing heart failure and severe blood loss (8).

Viperids present neutral proteins of different molecular masses, particularly of high mass enzymatic proteins. This includes enzymes such as proteases, esterases, L-amino oxidases, hyaluronidase, myotoxic phospholipases $\mathrm{A}_{2}$ and hemorrhagic factors $(9,10)$. Phospholipase $A_{2}$ in pit viper venom is responsible for cell membrane disruption (11). The predominance of enzymatic components in viperid venoms is strongly supported by other proteomics study as well (1214).

All the krait and cobra venoms showed lower cytotoxic potency towards both Vero and MDCK cell lines, in comparison to viper venoms. Our results corroborate the study 
by Nawarak et al. (15), who found differences between Elapidae and Viperidae protein profiles. Cobra venom consists of curare-like neurotoxins that block neurotransmission at postsynaptic nicotinic receptors in motor endplates. Besides a-bungarotoxin, which acts postsynaptically, the main constituent of krait venom is $\beta$-bungarotoxin, which contains phospholipase $A_{2}$ and exerts presynaptic action $(9,16)$. Toxins belonging to cardiotoxin and neurotoxin groups are low-molecular-weight proteins. Cardiotoxins are also shown to be involved in membrane depolarization and ultimate cytolysis in many tissue types via direct lytic factor (17).

Although it was expected that $\mathrm{OH}$ venom would also show low $\mathrm{CTC}_{50}$ values commonly found in cobras, the determined values fell between those of the viper and krait/cobra groups. Thus, even though king cobra is morphologically similar to other cobras with limited variation, it has been found to produce venom with a unique protein toxin which presents cardiotoxic and hemorrhagic characteristics. This suggests that unlike most Elapidae venoms which are non-hemorrhagic, $\mathrm{OH}$ venom exerts both hemorrhagic and proteolytic activities. These properties explain the high cytotoxicity of $\mathrm{OH}$ venom against both cell lines tested, almost comparable to that of viper venoms. The above claim is supported by Hawgood and Bon (18) and Gomes et al. (19).

$\mathrm{CTC}_{50}$ of ES was not detectable as it failed to show cytotoxicity towards either MDCK or Vero cells. These results might be attributable to the fact that sea snakes contain potent neurotoxins whereas $60 \%$ of the protein content in ES venom consists of highly potent postsynaptic neurotoxins (20). It is also important to note that the venoms of sea snakes are characterized by very low levels of enzymatic activities except for $\mathrm{PLA}_{2}$ and a total lack of L-amino acid oxidase or hemorrhagic activities (21).

There were no significant differences between the two cell lines used in this study. Biologically, the mammalian cell lines Vero and MDCK are closely related to their human counterparts. The Vero cell line is derived from kidney epithelial cells of the African green monkey whereas the MDCK line originates from Madin-Darby canine kidney cells. Both cell lines are mammalian kidney cells, commonly used in cytotoxicity experiments.

In conclusion, we demonstrated the possibility of successfully employing Vero and MDCK cell lines to study cytotoxicity of venoms with predominantly hemotoxic constituents common in vipers rather than cobras, kraits or sea snakes - capable of destroying cells or tissues.

\section{ACKNOWLEDGEMENTS}

The authors would like to acknowledge $\mathrm{Mr}$. Zainuddin of Bukit Bintang Enterprise for handling the snakes during venom milking.

\section{COPYRIGHT \\ (c) CEVAP 2012}

\section{SUBMISSION STATUS}

Received: June 26, 2011.

Accepted: October 21, 2011.

Abstract published online: October 26, 2011.

Full paper published online: May 31, 2012.

\section{CONFLICTS OF INTEREST}

The authors declare no conflicts of interest.

\section{FINANCIAL SOURCE}

The authors would like to acknowledge Monash University Sunway Campus for the grant (awarded in 2009) to complete this study.

\section{ETHICS COMMITTEE APPROVAL}

The experiments were conducted according to the ethics norm approved by the Animal Ethics Committee (AEC) of Monash Australia (AEC No: SOBCB/MY/2008/36).

\section{CORRESPONDENCE TO}

Jaya Vejayan, School of Medicine and Health Sciences, Monash University, Sunway Campus, Jalan Lagoon Selatan, 46150 Bandar Sunway, Selangor Darul Ehsan, Malaysia. Fax: +603 55146323. Email: jayavejayan@yahoo.com.

\section{REFERENCES}

1. Gutierrez JM, Williams D, Fan HW, Warrell DA. Snakebite envenoming from a global perspective: towards an integrated approach. Toxicon. 2010;56(7):1223-35.

2. Tan NH. The biochemistry of venoms of some venomous snakes of Malaysia: a review. Trop Biomed. 1991;8(1):91-103.

3. Bjarnason JB, Fox JW. Hemorrhagic toxins from snake venoms. J Toxicol Toxin Rev. 1989;7(2):121-209.

4. Bieber AL. Metal and nonprotein constituents in snake venoms. In: Lee CY, editor. Snake venoms. Handbook 
of experimental pharmacology. Berlin, Germany: Springer-Verlag; 1979. 295-306 p.

5. Warrell DA. Snake bite and snake venoms. Q J Med. 1993;86(6):351-3.

6. Oliveira JCR, Montes de Oca H, Duarte MM, Diniz CR, Fortes-Dias CL. Toxicity of South American snake venoms measured by an in vitro cell culture assay. Toxicon. 2002;40(3):321-5.

7. Kalam Y, Isbister GK, Mirtschin P, Hodgson WC, Konstantakapoulos N. Validation of a cell-based assay to differentiate between the cytotoxic effects of elapid snake venoms. J Pharmacol Toxicol Methods. 2011;63(2):137-42.

8. Persson $\mathrm{H}$. Envenoming by European vipers antivenom treatment-influence on morbidity. Persson Przegl Lek. 2001;58(4):223-5.

9. Barceloux DG. Terrestrial snakes (Suborder: Serpentes). In: Barceloux DG, editor. Medical toxicology of natural substances: foods, fungi, medicinal herbs, toxic plants, and venomous animals. Hoboken, NJ: John Wiley \& Sons; 2008. 1014 p.

10. Mackessy SP. Thrombin-like enzymes in snake venoms. In: Kini RM, McLane MA, Clemetson K, Markland FS, Morita T, editors. Toxins and hemostasis: from bench to bedside. Berlin, Germany: Springer-Verlag; 2011.

11. Norris RL. Envenomations. In: Irwin RS, Rippe JM, editors. Irwin and Rippe's intensive care medicine. Philadelphia, USA: Lippincott Williams and Wilkins; 2008. 1589 p.

12. Li S, Wang J, Zhang X, Ren Y, Wang N, Zhao K, et al. Proteomic characterization of two snake venoms: Naja naja atra and Agkistrodon halys. Biochem J. 2004;384(Pt 1):119-27.
13. Serrano SMT, Shannon JD, Wang D, Camargo ACM, Fox JW. A multifaceted analysis of viperid snake venoms by two-dimensional gel electrophoresis: an approach to understanding venom proteomics. Proteomics. 2005;5(2):501-10.

14. Angulo Y, Escolano J, Lomonte B, Gutiérrez JM, Sanz L, Calvete JJ.. Snake venomics of Central American pitvipers: clues for rationalizing the distinct envenomation profiles of Atropoides nummifer and Atropoides picadoi. J Proteome Res. 2008;7(2):708-19.

15. Nawarak J, Sinchaikul S, Wu CY, Liu MY, Phutrakul S, Chen ST.. Proteomics of snake venoms from Elapidae and Viperidae families by multidimensional chromatographic methods. Electrophoresis. 2003;24 (16):2838-54.

16. Kondo K, Toda H, Narita K. Amino acid sequence of phospholipase A from Bungarus multicinctus venom. J Biochem. 1981;89(1):37-47.

17. Huang SJ, Kwan CY. Inhibition by multivalent cations of contraction induced by Chinese cobra venom cardiotoxin in guinea pig papillary muscle. Life Sciences. 1996;59(4):55-60.

18. Hawgood B, Bon C. Snake venom presynaptic toxins. In: Tu AT, editor. Reptile venom and toxins: handbook of natural toxins. New York: Marcel Dekker Co; 1991. 611-39 p.

19. Gomes A, Pallabi D, Dasgupta SC. Occurrence of a unique protein toxin from the Indian King Cobra (Ophiophagus hannah) venom. Toxicon. 2001; 39(23):363-70.

20. Tu AT. Sea snake venoms and neurotoxins. J Agric Food Chem. 1974; 22(1):36-43.

21. Takasaki C. The toxinology of sea snake venoms. Toxin Reviews. 1998; 17(3):36. 